\title{
Hypertension management in Canada: good news, but important challenges remain
}

\author{
Sailesh Mohan MD MPH, Norm R.C. Campbell MD
}

$\infty$

See related articles, pages I429, I436 and I44I

$\mathrm{T}$ hree research articles in this issue of CMAJ bring evidence of marked improvements in the diagnosis and treatment of hypertension in Ontario, Canada's most populous province. ${ }^{1-3}$ The findings will have a major impact on health care professionals interested in cardiovascular disease, public health and hypertension worldwide. Those in the Canadian health care system, particularly the primary care system, can be proud to be setting benchmarks for the management of this leading cause of death. Nevertheless, substantial challenges remain.

The prevalence of hypertension continues to increase globally. In the Framingham heart study, the lifetime risk for hypertension among middle-aged normotensive adults was estimated to be $90 \%{ }^{4}{ }^{4}$ Typically, most cases of hypertension either are not diagnosed or go untreated. The condition is a key contributor to the development of cardiovascular and cerebrovascular disease, with nearly two-thirds of all cases of stroke and one-half of all cases of ischemic heart disease being directly attributable to hypertension. ${ }^{5}$ This gap in prevention and management represents a major public health failure worldwide. ${ }^{5,6}$

In the first 2 research articles in this issue, Tu and colleagues report on trends in the prevalence and incidence of hypertension and associated mortality among adults aged 20 years and older in the province of Ontario using linked administrative data. ${ }^{1,2}$ They found that the age- and sexadjusted prevalence of hypertension increased by $60.0 \%$ (from I53.I per 1000 in 1995 to 244.8 per 1000 in 2005) and that the age- and sex-adjusted incidence increased by $25.7 \%$ (from 25.5 per 1000 in 1997 to 32.1 per 1000 in 2004). ${ }^{1}$ Because the increase in prevalence markedly exceeded predictions, the authors examined whether it was associated with a large increase in cardiovascular disease burden. During the same period, they found a $15.5 \%$ reduction in the age- and sex-adjusted mortality among patients with hypertension. ${ }^{2}$ This finding suggests that the increased prevalence of hypertension was due to both an increase in incidence and a decline in mortality.

In the third article, Leenen and colleagues ${ }^{3}$ present their findings from the Ontario Survey on Prevalence and Control of Hypertension (ON-BP), which examined the prevalence, treatment and control of hypertension among 255I adults in
Ontario. They found that the prevalence of hypertension was $21 \%$ among the respondents and that $52 \%$ of those aged 6o-79 years had hypertension. Two-thirds of the people with hypertension were receiving antihypertensive treatment and had blood pressure control. Compared with data from previous Canadian studies, the authors found that the mean systolic and diastolic blood pressures were substantially lower, particularly among those aged 60 years and older.

One of the most important findings from the ON-BP study is the remarkable improvement in hypertension management. The reported hypertension awareness rate of $87 \%$, treatment rate of $82 \%$, and treatment and control rate of $66 \%$ are by far the highest from any population-based study. In comparison, the second highest rates reported to date were from a province in Cuba, where $78 \%$ of the respondents who had hypertension stated that they were aware of their condition, $60 \%$ received treatment, and $40 \%$ received treatment and had blood pressure control. ${ }^{7}$ The results reported by Leenen and colleagues indicate a vast change compared with the findings of the 1985-1992 Canadian Heart Health Survey, which reported a treatment and control rate of $13 \%{ }^{8}$ The latest American survey found a treatment and control rate of $37 \%$, and comparable studies from Europe indicated that less than $25 \%$ of people with hypertension receive adequate treatment. ${ }^{9,10}$

The ON-BP study also provides important insights into ethnic background and hypertension. South Asian and female black Canadians had a disproportionately high prevalence of hypertension. This indicates the need for tailored interventions to prevent hypertension at the community and individual levels. The new Canadian initiative to lower the amount of sodium in prepared foods may be important to reduce hypertension prevalence in these populations. ${ }^{11} \mathrm{It}$

The authors are with the Departments of Medicine and Community Health Sciences, University of Calgary; Norm Campbell is also with the Department of Pharmacology and Therapeutics, Libin Cardiovascular Institute, University of Calgary, Calgary, Alta.

Une version française de cet article est disponible à l'adresse www.cmaj.ca/cgi/content/full/I78/II/I458/DCI 
is reassuring that the ON-BP study found similar levels of treatment and control in different ethnic groups, an issue the American health care system has not yet successfully dealt with. ${ }^{9}$

The high and increasing prevalence of hypertension reported by $\mathrm{Tu}$ and colleagues ${ }^{1}$ is in contrast with the lower prevalence reported by Leenen and colleagues. ${ }^{3}$ One of the strengths of the study by Tu and colleagues is that the authors used administrative data to identify all adults with physiciandiagnosed hypertension in Ontario and follow them over time. However, some caveats are required for interpreting their results. In clinical practice, initial blood pressure assessments often overestimate blood pressure and may lead to billings for hypertension but no diagnosis of hypertension. ${ }^{12,13}$ Administrative data, therefore, may overestimate the prevalence of hypertension because of Ontario's high rate of awareness. Furthermore, the sharp increase in the incidence of hypertension after 1999 reported by Tu and colleagues coincides with the introduction of the Canadian Hypertension Education Program and probably represents an increase in the detection of hypertension rather than a true increase in its incidence. ${ }^{14}$ It is interesting that $\mathrm{Tu}$ and colleagues report a reduction in mortality among people with hypertension at about the same time as the rapid increase in incidence. ${ }^{2}$ This occurrence could be because more cases of hypertension in lower-risk patients were diagnosed or because of improvements in the management of hypertension, as documented by Leenen and colleagues, or both.

The study by Leenen and colleagues also requires some caveats. The technique by which blood pressure was assessed is associated with less "white coat" hypertension than manual methods used in previous surveys, which may explain in part why the prevalence of hypertension was lower in their study than in the previous studies. ${ }^{15}$ The lower rate of participation in the study by Leenen and colleagues compared with earlier surveys raises concerns that the respondents may not be representative of all Ontarians and that populations with high prevalence rates of hypertension may not have been fully represented. To verify and assess the generalizability of the results of the ON-BP study, we will have to wait for the release of the Canadian Health Measures Survey in 2010.

Accumulating evidence shows marked improvements in the diagnosis and treatment of hypertension in Canada since the start of the Canadian Hypertension Education Program. ${ }^{14,16,17}$ This extensive knowledge-translation program provides guidance based on up-to-date evidence for hypertension management. It is tailored to primary care health professionals and is coupled with an expanding outcomes evaluation program. ${ }^{18-20}$ More recently, an expanding public education program has been established by Blood Pressure Canada. The improvement in hypertension care and the usefulness of effective education programs for health care professionals such as the Canadian Hypertension Education Program could serve as an example for other countries, both developed and developing, and could be generalized to improving the management of other risk factors.

Although the evidence in this issue indicates that the di- agnosis and management of hypertension have improved, the ON-BP survey clearly indicates that more needs to be done. Leenen and colleagues found that $\mathrm{I}$ in 3 adults with hypertension did not have blood pressure control. They also found that two-thirds of adults at high risk for cardiovascular disease because of comorbid diabetes and hypertension did not have blood pressure control and that over onequarter had received no treatment. Of note, more intensive treatment of hypertension in patients with diabetes can actually save the health care system money as well as preventing death and disability. ${ }^{21}$ Furthermore, control of systolic blood pressure was recently reported to have been achieved in only $58 \%$ of patients with known cardiovascular disease and who were at high risk for further events. ${ }^{22}$ Perhaps one of the most important challenges is the prevention of hypertension. Although hypertension is preventable, it is estimated that the the condition will develop in $90 \%$ of Canadians. ${ }^{4}$ These are important challenges, and there is much that can be done to improve health through prevention and control of hypertension.

Competing interests: Norm Campbell has received speaker fees from Biovail, Boehringer Ingelheim, Bayer, Pfizer and Novartis; honoraria from Servier Canada for chairing symposia; consulting fees from Novartis, Pfizer, Servier Canada and Boehringer Ingelheim; and travel assistance from Servier Canada. No competing interests declared by Sailesh Mohan.

Contributors: Both authors contributed substantially to the content of the manuscript. Sailesh Mohan drafted the initial manuscript, which was revised by Norm Campbell. Both authors have approved the final version to be published.

Acknowledgements: Sailesh Mohan is supported by the Canadian Institutes of Health Research (CIHR) Canada-HOPE Fellowship. Norm Campbell is supported by the CIHR Canada Chair in Hypertension Prevention and Control.

\section{REFERENCES}

I. Tu K, Chen Z, Lipscombe LL; Canadian Hypertension Education Program Outcomes Research Taskforce. Prevalence and incidence of hypertension from I995 to 2005: a population-based study. $C M A J$ 2008;178:I429-35.

2. Tu K, Chen Z, Lipscombe LL; Canadian Hypertension Education Program Outcomes Research Taskforce. Mortality among patients with hypertension from 1995 to 2005: a population-based study. CMAJ 2008;178:1436-40.

3. Leenen FHH, Dumais J, McInnis NH, et al. Results of the Ontario Survey on the Prevalence and Control of Hypertension. $C M A J$ 2008;178:I44I-9.

4. Vasan RS, Beiser A, Seshadri S, et al. Residual lifetime risk for developing hypertension in middle-aged women and men: the Framingham heart study. JAMA 2002;287:1003-10.

5. Lawes CM, Vander Hoorn S, Law MR, et al. Blood pressure and the global burden of disease 2000. Part II: Estimates of attributable burden. J Hypertens 2006; 24:423-30.

6. World Health Organization. The world health report 2002. Reducing risks, promoting healthy life. Geneva: The Organization; 2002.

7. Orduñez-Garcia P, Munoz JL, Pedraza D, et al. Success in control of hypertension in a low-resource setting: the Cuban experience. J Hypertens 2006;24:845-9.

8. Joffres MR, Ghadirian P, Fodor JG, et al. Awareness, treatment, and control of hypertension in Canada. Am J Hypertens I997;10:1097-I02.

9. Ong KL, Cheung BMY, Man YB, et al. Prevalence, awareness, treatment, and control of hypertension among United States adults 1999-2004. Hypertension 2007; 49:69-75.

Io. Pavlik VN, Hyman DJ. How well are we managing and monitoring high blood pressure? Curr Opin Nephrol Hypertens 2003;12:299-304.

II. Campbell NR. Canada Chair in Hypertension Prevention and Control: a pilot project. Can J Cardiol 2007;23:557-6o.

I2. Campbell NR, McKay DW. Accurate blood pressure measurement: Why does it matter? CMAJ I999;I61:277-8.

I3. McKay DW, Campbell NR, Parab LS, et al. Clinical assessment of blood pressure. J Hum Hypertens 1990;4:639-45.

I4. Onysko J, Maxwell C, Eliasziw M, et al.; Canadian Hypertension Education Pro- 
gram. Large increases in hypertension diagnosis and treatment in Canada after a healthcare professional education program. Hypertension 2006;48:853-60.

15. Myers MG, Godwin M. Automated measurement of blood pressure in routine clinical practice. JClin Hypertens 2007;9:267-70.

I6. Campbell NR, Tu K, Brant R, et al.; Canadian Hypertension Education Program Outcomes Research Task Force. The impact of the Canadian Hypertension Education Program on antihypertensive prescribing trends. Hypertension 2006; 47:22-8.

I7. Campbell NR, McAlister FA, Brant R, et al.; Canadian Hypertension Education Process and Evaluation Committee. Temporal trends in antihypertensive drug prescriptions in Canada before and after introduction of the Canadian Hypertension Education Program. J Hypertens 2003;21:I59I-7.

I8. McAlister FA. The Canadian Hypertension Education Program - a unique Canadian initiative. Can J Cardiol 2006;22:559-64.

I9. Drouin D, Campbell NR, Kaczorowski J. Implementation of recommendations on hypertension: the Canadian Hypertension Education Program. Can J Cardiol 2006; 22:595-8.
20. Campbell N, Onysko J; Canadian Hypertension Education Program Outcomes Research Task Force. The Outcomes Research Task Force and the Canadian Hypertension Education Program. Can J Cardiol 2006;22:556-8.

2I. CDC Diabetes Cost-effectiveness Group. Cost-effectiveness of intensive glycemic control, intensified hypertension control, and serum cholesterol level reduction for type 2 diabetes. JAMA 2002;287:2542-5I.

22. Hackam DG, Leiter LA, Yan AT, et al.; Vascular Protection Registry and Guideline Oriented Appraoch to Lipid Lowering Registry Investigators. Missed opportunities for the secondary prevention of cardiovascular disease in Canada. Can J Cardio 2007;23:1124-30.

Correspondence to: Dr. Norm R.C. Campbell, Departments of Medicine, Community Health Sciences, and Pharmacology and Therapeutics, Libin Cardiovascular Institute, University of Calgary, Calgary AB T2N 4NI; fax 403 283-6I5I; ncampbel@ucalgary.ca

\section{Implement the COPD Guidelines into your practice}

The simple way to provide your patients with optimal care

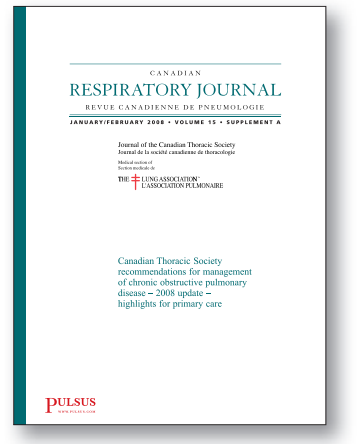

2008 Update: Recommendations for the Management of Chronic Obstructive Pulmonary Disease (COPD) - Highlights for Primary Care* from the Canadian Thoracic Society (CTS) - evidence based guidelines to optimize prevention, early diagnosis, and management of COPD in Canada:

- Use targeted screening and spirometry to establish an early diagnosis and initiate treatment

- Improve dyspnea and activity limitation in stable COPD by optimizing pharmacologic and non pharmacologic management strategies

- Prevent and manage acute exacerbations of COPD

*Published in 2008 in the Canadian Respiratory Journal www.pulsus.com.

For your copy of the COPD Update and information about COPD management visit: www.respiratoryguidelines.ca and refer your patients to The Lung Association Information Line 1-866-717-COPD (2673) [English] 1-866-717-MPOC (6762) [French] 